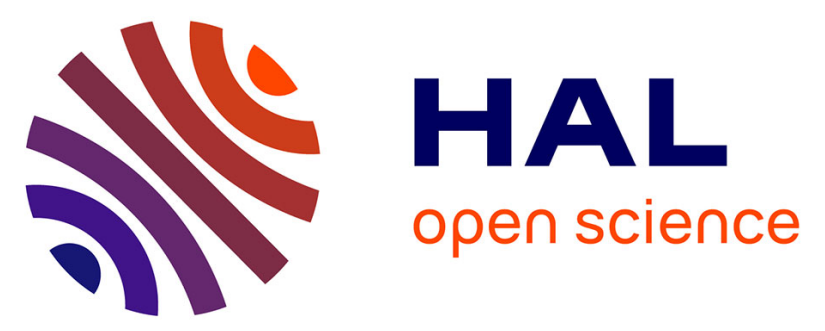

\title{
Implementation and Experimental Validation of Robust Numerical Control for DC-DC Buck Converter
}

Abdivall Maouloud, Moussa Boukhnifer, Cherif Larouci, Hichame Maanane, Fabien Simon

\section{- To cite this version:}

Abdivall Maouloud, Moussa Boukhnifer, Cherif Larouci, Hichame Maanane, Fabien Simon. Implementation and Experimental Validation of Robust Numerical Control for DC-DC Buck Converter. 2019 6th International Conference on Control, Decision and Information Technologies (CoDIT), Apr 2019, Paris, France. pp.912-917, 10.1109/CoDIT.2019.8820464 . hal-03246252

\section{HAL Id: hal-03246252 \\ https://hal.science/hal-03246252}

Submitted on 2 Jun 2021

HAL is a multi-disciplinary open access archive for the deposit and dissemination of scientific research documents, whether they are published or not. The documents may come from teaching and research institutions in France or abroad, or from public or private research centers.
L'archive ouverte pluridisciplinaire HAL, est destinée au dépôt et à la diffusion de documents scientifiques de niveau recherche, publiés ou non, émanant des établissements d'enseignement et de recherche français ou étrangers, des laboratoires publics ou privés. 


\title{
Implementation and Experimental Validation of Robust Numerical Control for DC-DC Buck Converter*
}

\author{
Abdivall Maouloud ${ }^{1}$, Moussa Boukhnifer ${ }^{1}$, Cherif Larouci ${ }^{1}$, Hichame Maanane ${ }^{2}$, Fabien Simon ${ }^{2}$ \\ ${ }^{1}$ ESTACA Campus Paris-Saclay, France \\ abdivall@yahoo.fr, moussa.boukhnifer@estaca.fr, cherif.larouci@estaca.fr \\ 2 THALES LAS OME, Elancourt, France \\ hichame.maanane@fr.thalesgroup.com, fabien.simon@fr.thalesgroup.com
}

\begin{abstract}
This paper deals with a global study of numerical control implementation applied to a DC-DC buck converter with two techniques, classical control technique (PI control) and robust control technique (H-infinity loop-shaping control). The $\mathrm{H}$-infinity loop-shaping control is applied to improve the performance and the stability robustness of this power converter based on pulse-width-modulation (PWM) techniques. The experimental results are very promising. They show that $\mathrm{H}-$ infinity loop-shaping control performs better than PI control. Hinfinity loop-shaping control reject disturbance and noise produce by the DC-DC power converter. In addition to experimental validation, the other added value of this paper is to demonstrate the feasibility of easily implementing robust numerical controls allowing rejecting disturbances without real impact on computing time, which is very important for embedded power converter applications.
\end{abstract}

\section{INTRODUCTION}

The DC-DC switching power converters present an essential part of power supply systems and there are used in many electronics equipment's. The feedback controller of such a DC-DC converter is a digital or analog design. The potential advantages of digital control implementation include much improved flexibility, reduced design time, programmability, and easier system integration. However, the main disadvantage of numerical control power supplies is the sensibility to noise disturbance [1][2].

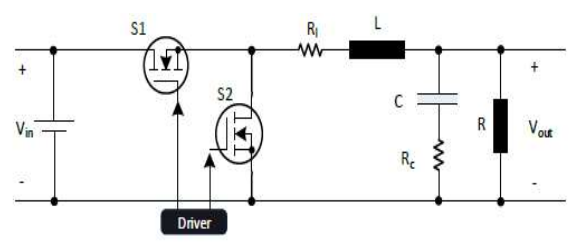

Fig. 1. Buck converter [5]

Power supplies employ different techniques in their control methodology. Voltage mode control (VMC) (see Fig.2) and current mode control (CMC) (see Fig.3) are the popular methods of controlling power supplies.

The VMC consists on comparing error between the output voltage and the reference voltage to a constant ramp waveform with fixed frequency. The feedback function of the voltage control loop modulates the duty cycle of the PWM, so that the target output voltage is maintained. However, measuring the output voltage means that any change on the load variation must be sensing and then corrected by the control loop [4]. Though the load variation change does not have an immediate impact on the output voltage, slowing down the transient response.

The mentioned problem that occurs in VMC can be somehow circumvented using CMC (Fig 2). In a buck converter, the inductor current is proportional to Vin-Vout, meaning that any change on the input or output voltages will be immediately sensed, improving the control loop speed [5][6]. For the current sensing, an additional circuitry is needed.

Different CMC methods were developed: The average current control (ACC) and the Peak current control (PCC) are both different techniques to control system. Therefore, in ACC case, the average current of the inductor modulates the duty cycle of the PWM to maintain the output voltage. In the other hand with the PCC case, the steady state duty-cycle-to-output transfer function in peak current control is maintained by two essential control loops - one inherent loop, reacting to limit current detections and one coherent loop that reflects output vs. reference deviations, adjusting the limit current.

Furthermore, at duty cycles above $50 \%$, this method becomes unstable and results in sub-harmonic oscillation. Subharmonic oscillation can occur when the inductor current suffers a perturbation. At duty cycles above $50 \%$, as can be observed, the current will not converge to the steady state value, causing the

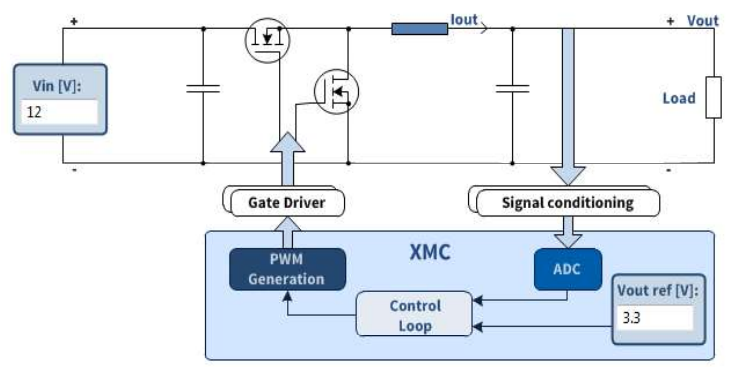

Fig. 2. Voltage mode control buck converter [12]

oscillations. To damp such oscillation, slope compensation is usually employed, but such approach may result in some 
performance degradation in response to fast load changes [7][8][9][10].

In this paper, we use PCC methodology.

Table 1 summarizes the advantages and the disadvantages of the referenced control methods [5] [12].

\begin{tabular}{|c|c|c|}
\hline Method & Advantages & Disadvantages \\
\hline VMC & $\begin{array}{c}\text { Simplicity } \\
\text { No additional } \\
\text { components required }\end{array}$ & $\begin{array}{c}\text { Slow response to load } \\
\text { variations }\end{array}$ \\
\hline PCC & $\begin{array}{c}\text { Fast transient } \\
\text { response }\end{array}$ & $\begin{array}{c}\text { Oscillations at } \mathrm{d}<50 \% . \\
\text { Need slope compensation } \\
\text { Need a comparator } \\
\text { blanking mechanism }\end{array}$ \\
\hline VCC & $\begin{array}{c}\text { Cycle-by-cycle } \\
\text { current limitation } \\
\text { No need for blanking } \\
\text { of the compensators }\end{array}$ & $\begin{array}{c}\text { Oscillations at } \mathrm{d}<50 \% \\
\text { Need slope compensation } \\
\text { Poor line regulation } \\
\text { Slower than PCC }\end{array}$ \\
\hline ACC & $\begin{array}{c}\text { No sub-harmonic } \\
\text { oscillations }\end{array}$ & $\begin{array}{c}\text { Slow transient response } \\
\text { Difficult to measure the } \\
\text { average value }\end{array}$ \\
& & \\
\hline
\end{tabular}

The purpose of this paper is to describe the best techniques of digital control implementation of on Infineon microcontroller XM4200. In fact, in order to reduce and characterize the noise level on output signal in case, different controller types are used such as PI, 3P3Z and H-Infinity controller.

\section{BUCK COMPENSATOR ARCHITECTURE}

The buck converter Fig. 1 contains a switching cell composed of two MOSFET transistors controlled by a PWM strategy [12].

The inductor (eq.1) smooths the current in the circuit and the capacitance (eq.2) limits the output voltage ripple.

The output stage stores and delivers energy to the load and produces a constant output voltage.

$$
C=\frac{\alpha(1-\alpha) V_{i n}}{L . \Delta V_{0} \cdot F_{d}^{2}}
$$

$$
L=\frac{\alpha(1-\alpha) V_{i n}}{F_{d} \Delta I_{l}}
$$

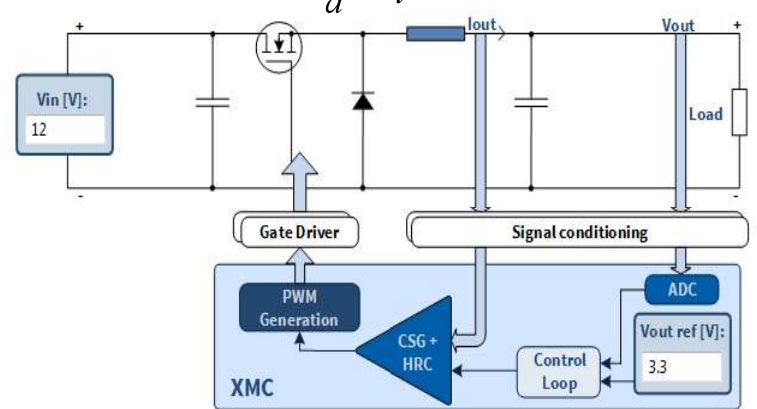

Fig. 3. Current-voltage mode control buck converter [12]
Inductors and capacitors have a dc resistance (DCR) which impacts the performance of the output stage (Fig.1). Minimizing the DCR improves the overall efficiency of the converter. The test board DCR value giving by the manufactory is very low. Therefore, simulation study shows that we can ignore DCR value because it is negligible, so we have not introduced this value in the buck converter final model.

In this case, the transfer function of the ideal dynamical model buck dc-dc converter is given by (eq.3):

With: $\quad H(S)=\frac{\operatorname{Vout}(S)}{\alpha(S)}=\frac{V_{\text {in }}}{1+\frac{L}{R} S+L C S^{2}}$

$\alpha \quad$ duty cycle

$V$ in input voltage

$V$ out output voltage

$\Delta V_{0}$ output voltage variation

$\Delta I_{l} \quad$ inductor ripple-current

$F_{d} \quad$ switching frequency

L filter inductance

C filter capacitance

$\mathrm{R} \quad$ load resistance

The natural frequency $\omega_{0}$ and damping factor $\zeta$ are given by:

$\xi=\frac{1}{2 R} \sqrt{\frac{L}{C}}$

$\omega_{O}=\sqrt{\frac{1}{L C}}$

The objective of the compensator in feedback control loop is to add the necessary mechanism for helping the system output to track a desired reference even in the presence of noise, modeling error or disturbances. Fig. 4 represents a typical system control diagram for a switch-mode power supply. The modulator generates the pulses needed to maintain the steady state duty-cycle-to-output-voltage transfer function of the sense-modulate-drive control loop. There is also an output filter, typically comprising an inductor, capacitor, a compensator and a voltage reference to regulate the output voltage.

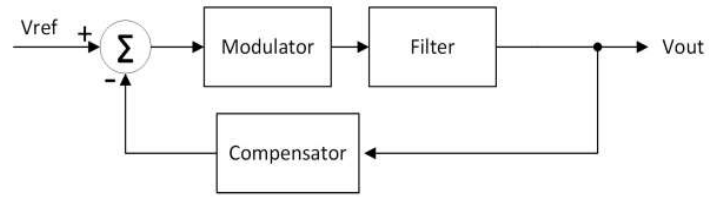

Fig. 4. System control diagram [12] 
The output of the modulator is a rectangle wave. This rectangle is averaged by the output filter and applied to the load as a DC voltage. In the following, we compare 3P3Z (3 poles, 3 zeros) controller performance with $\mathrm{PI}$ and $\mathrm{H}$-infinity controller performance to find the most suitable feedback controller for voltage-controlled buck converters. The poles and zeros of the compensation networks should be placed according to the analysis of the control output transfer function. We first optimize the design for the controllers for 3 methods, then, we simulate (section III) the performance and run some experimentations (section IV)

\section{A. Proportionnal Integral (PI) controller}

The proportional integral is widely used in industrial control systems because of the reduced number of parameters to be tuned. They provide control signals that are proportional to the error between the reference signal and the actual output (proportional action), with the integral of the error (integral action) (see Fig. 5).

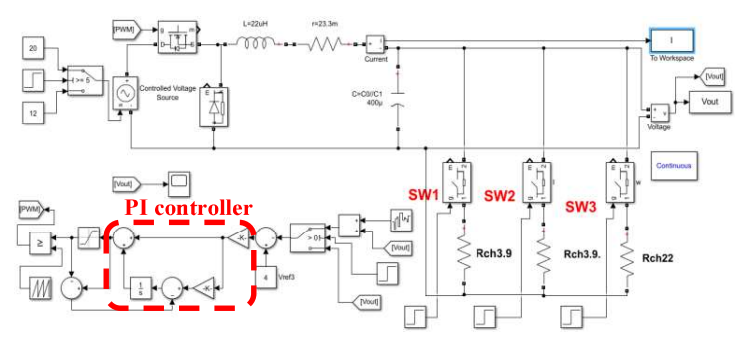

Fig. 5. Buck converter with PI controller

The structure of PI controller in " $\mathrm{S}$ " domain is

$$
C(S)=K p+K i / S
$$

The bilinear transformation has been used in order to get the discrete form of the PI controller transfer function. The variable " $S$ " has been substituted in (6) by [14]:

$$
S=\frac{2}{T e} * \frac{Z-1}{Z+1}
$$

With, Te is the controller-sampling period.

Substituting (7) into (6) give the discrete PI controller transfer function:

$$
C(Z)=\frac{\left(K p+\frac{T e \cdot K i}{2}\right) Z+\left(-K p+\frac{T e \cdot K i}{2}\right)}{Z-1}
$$

Based on standard model of converter [3], the parameters $(\mathrm{Kp}=0.5$ and $\mathrm{Ki}=544.5)$ of PI controller have been designed and with the choice of $\mathrm{Te}=41.6 \mu \mathrm{s}$ in order to respect the Shannon theorem, the resulting discrete controller transfer function is given as follows:

$$
C(Z)=\frac{-0.4887 Z^{-1}+0.5113}{-Z^{-1}+1}
$$

On the other hand, the general discrete form of the Infineon controller is given by the expression (eq. 10):

$$
C(Z)=\frac{B_{3} Z^{-3}+B_{2} Z^{-2}+B_{1} Z^{-1}+B_{0}}{-A_{3} Z^{-3}-A_{2} Z^{-2}-A_{1} Z^{-1}+1}
$$

So, for the PI controller:

$$
B_{0}=0.5113, B_{1}=0.4887, A_{1}=1
$$

\section{B. $3 P 3 Z$ ( 3 poles, 3 zeros) Controller}

Infineon design this $3 \mathrm{P} 3 \mathrm{Z}$ controller; we use Tustin transformer to find the continuous form of this controller in order to implement it in buck converter voltage loop.

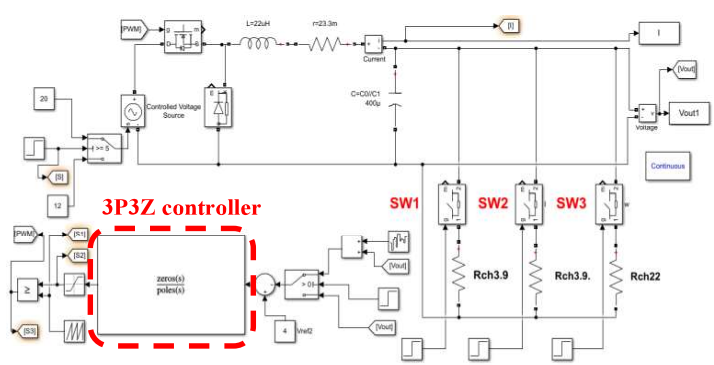

Fig. 6. Buck converter with 3P3Z controller

The structure of $3 \mathrm{P} 3 \mathrm{Z}$ controller in " $\mathrm{Z}$ " domain is given by [12]:

$$
K(Z)=\frac{1,48 Z^{-3}-1,58 Z^{-2}-1,47 Z^{-1}+1.6}{0,17 Z^{-3}+0,36 Z^{-2}-1,53 Z^{-1}+1}
$$

With the bilinear transformation, the resulting continuous controller 3P3Z transfer function is below:

$$
K(S)=\frac{9,9710^{-16} S^{3}+2,1610^{5} S^{2}+3,6810^{8} S+1,2910^{11}}{S^{3}+8,2310^{4} S^{2}+5,1610^{8} S-4,0810^{7}}
$$

\section{H-infinity Loop Shaping Controller}

$\mathrm{H}$-infinity loop shaping control is an efficient method to design a robust controller. This approach requires only a desired open loop shape in frequency domain, which is specified by the weighting functions, pre-compensator $\left(\mathrm{W}_{1}\right)$ and post-compensator $\left(\mathrm{W}_{2}\right)$. The uncertainty model of the system is formulated as normalized co-prime factors that divide the shaped plant (Gs) into nominator factor (Ns) and denominator factor (Ms) which is shown in Fig.7. Consequently, the shaped plant can be written as [11][13]:

$$
\begin{gathered}
G_{S}=W_{1} * G * W_{2} \\
G_{S}=\left(N_{S}+\Delta_{N S}\right)\left(M_{S}+\Delta_{M s}\right)^{-1}
\end{gathered}
$$

With G is the transfer function of the system, $\Delta_{\mathrm{Ns}}$ and $\Delta_{\mathrm{Ms}}$ 
are the uncertainty transfer functions in the nominator and denominator factors, respectively.

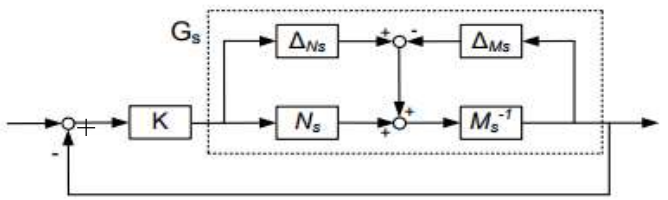

Fig. 7. H-infinity loop shaping control design [13]

In this approach, the pre-compensator $\left(\mathrm{W}_{1}\right)$ and post compensator $\left(\mathrm{W}_{2}\right)$ weights for achieving the desired loop shape are defined to obtain the optimal stability margin.

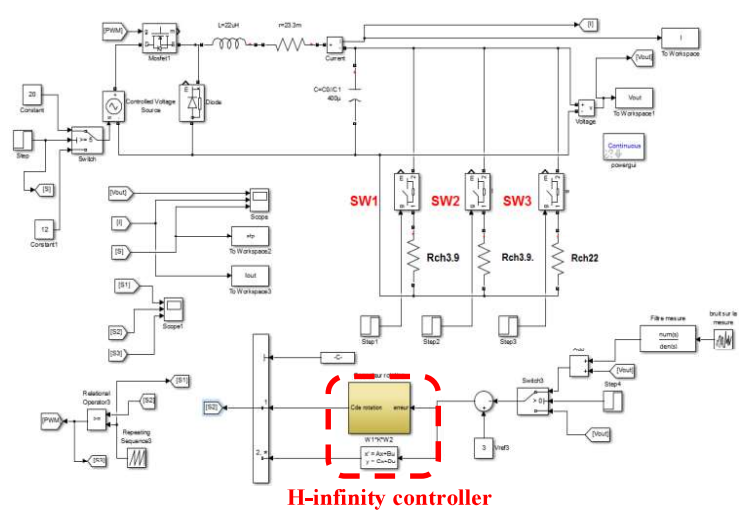

Fig. 8. Buck converter with H-infinity loop shaping controller

We have used the toolbox robust control of Matlab and the function (ncfsyn) to synthesize the $\mathrm{H}$-infinity loop shaping controller.

The structure of H-infinity loop shaping controller in " $Z$ " domain is given by:

$$
K(Z)=\frac{1,19 Z^{-3}+3,57 Z^{-2}+3,57 Z^{-1}+1.19}{-0,648 Z^{-3}+2,257 Z^{-2}-2,609 Z^{-1}+1}
$$

\section{SiMULATION RESULTS}

In Matlab Simulink diagram, we have added a noise disturbance to the feedback loop control. This method allows observing the influence of noise on the output of the buck converter in case a classical controller (PI, 3P3Z) or a robust controller (H-infinity loop shaping) is used.

With the loop-shaping controller, it is possible to reduce the noise effect on of the system output. The system specifications for the simulation of a buck regulator are given in Table II.

\section{A. Noise effect on classical control}

In this section the output voltage level is fixed on $4 \mathrm{~V}$, the noise is added at $\mathrm{t}=0,5 \mathrm{~s}$ to compare the noise effect on classical controllers PI and 3P3Z.

\begin{tabular}{|c|c|c|}
\hline Symbol & Parameter & Value \\
\hline Vin & Input voltage & $12 \mathrm{~V} \mathrm{DC}$ \\
\hline Vout & output voltage & $3.3 \mathrm{~V} \mathrm{DC}$ \\
\hline Iout $_{m a}$ & $\begin{array}{l}\text { Maximum output } \\
\text { current }\end{array}$ & $2 \mathrm{~A}$ \\
\hline$R$ & $\begin{array}{l}\text { On board load } \\
\text { values }\end{array}$ & $3.9 \Omega$ \\
\hline$L$ & Main inductor & $22 \mathrm{uF}$ \\
\hline $\mathrm{C}$ & Output capacitor & $400 \mathrm{uF}$ \\
\hline
\end{tabular}

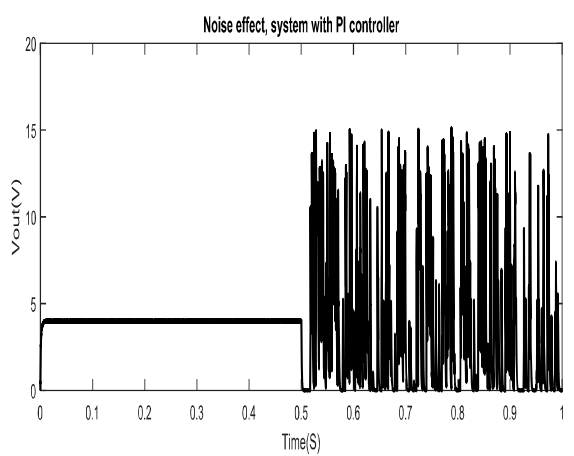

Fig. 9.a System with PI controller

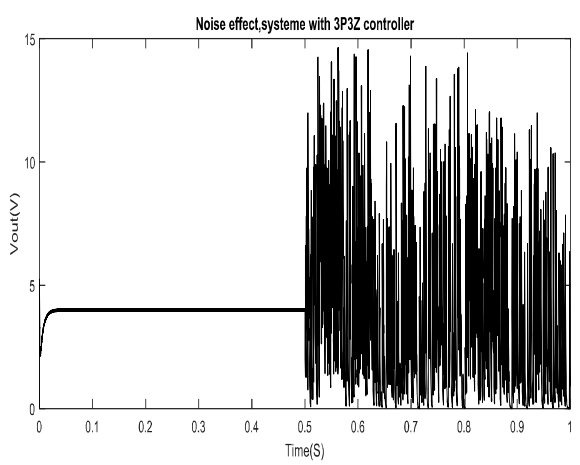

Fig. 9.b System with 3P3Z controller

The Fig. 9.a represents the simulation response of the buck converter with PI controller and the Fig. 9.b represents the buck converter simulation response with $3 \mathrm{P} 3 \mathrm{Z}$ controller.

Therefore, simulation results show that both controllers cannot regulate the output voltage because the classical controllers (PI and 3P3Z) are not robust against noise disturbance.

\section{B. Noise effect on robust control}

The objective of this final simulation is to prove the effectiveness of the $\mathrm{H}$-infinity robust controller in faulty mode when the system is affected by noise disturbance. The simulation test is a good way to validate the mathematical controller model before implementation on the microcontroller. The blue curve (Fig. 10) represents the output voltage of buck converter with PI controller. The red curve represents the output voltage with $\mathrm{H}$-infinity controller. The noise disturbance is added at $\mathrm{t}=1 \mathrm{~s}$. In addition the 
simulation results show that the $\mathrm{H}$-infinity controller rejects perfectly the white noise and ensures a good robustness stability.

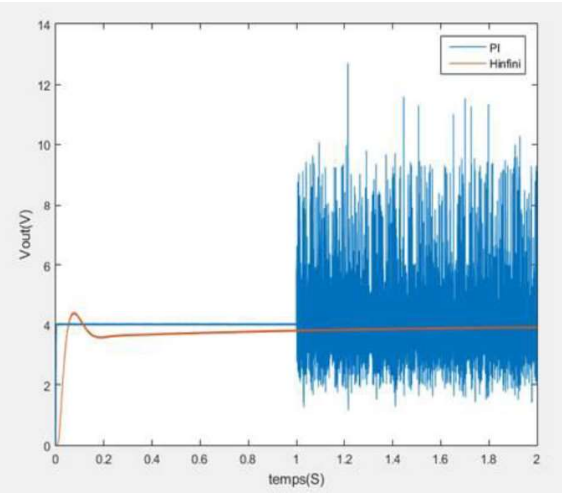

Fig. 10. Noise effect, buck converter response with PI and H- Infinity controller

\section{EXPERIMENTAL RESULTS}

This section presents the experimental validation of the theoretical controllers given in the previous section. It starts by describing the testing setup, including hardware descriptions and the test procedures.

\section{A. Infenion XMC4200 Kit description}

The XMC Digital Power Explorer Kit utilizes Infineon's industry leading $\mathrm{XMC}$ range of $\mathrm{ARM}{ }^{\circledR}$ Cortex ${ }^{\circledR}-\mathrm{M}$ microcontrollers, OptiMOS ${ }^{\mathrm{TM}}$ BSC0924NDI MOSFETs and IRS2011S high and low side drivers. The kit's power board features synchronous buck converter with on-board resistive load banks. The load banks can be switched between $10 \%$, $55 \%$ and $100 \%$ of the maximum load, so that the transient response and the quality of the control loop under different load conditions can be tested (for example continuous conduction mode vs. discontinuous conduction mode). The kit also includes 2 different control card options, XMC1300 control card (ARM ${ }^{\circledR}$ Cortex $\left.{ }^{\circledR}-\mathrm{M} 0\right)$ and XMC4200 control card (ARM ${ }^{\circledR}$ Cortex $\left.{ }^{\circledR}-\mathrm{M} 4 \mathrm{~F}\right)$ with isolated on-board debugger, which allow designers to easy evaluate both XMC microcontroller families and make the right price/performance choice for their application. Multiple test points are provided on the power board for checking the quality of all the relevant signals. Communication option via PMBus $^{\mathrm{TM}}$ is provided for easy integration in more complex power management systems [12].

\section{B. Quantization effect}

This first experience concerns the quantification effect. In this section we observe the experimental response of the buck converter with a PI controller and $3 \mathrm{P} 3 \mathrm{Z}$ controller.

Thererfore, the used microcontroller to implement the PI and $3 \mathrm{P} 3 \mathrm{Z}$ controllers is XMC4200. With, the voltage reference $\mathrm{Vref}=5 \mathrm{~V}$ ant the sampling frequency fs $=13,33 \mathrm{MHz}$.

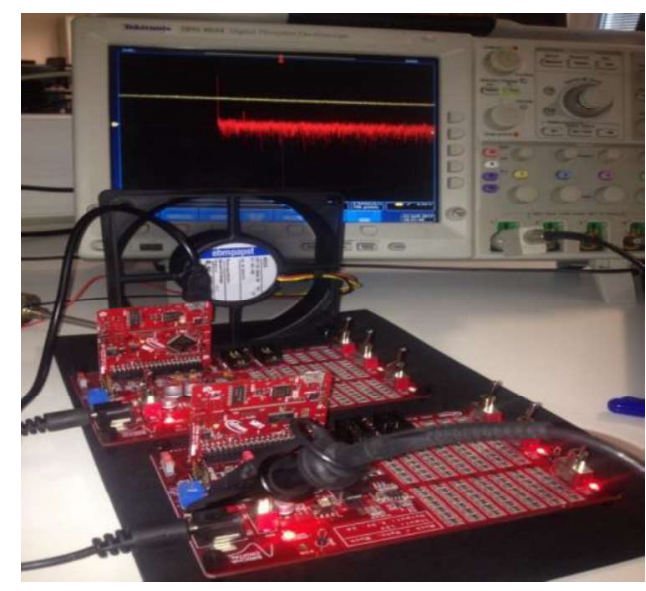

Fig. 11. XMC digital board

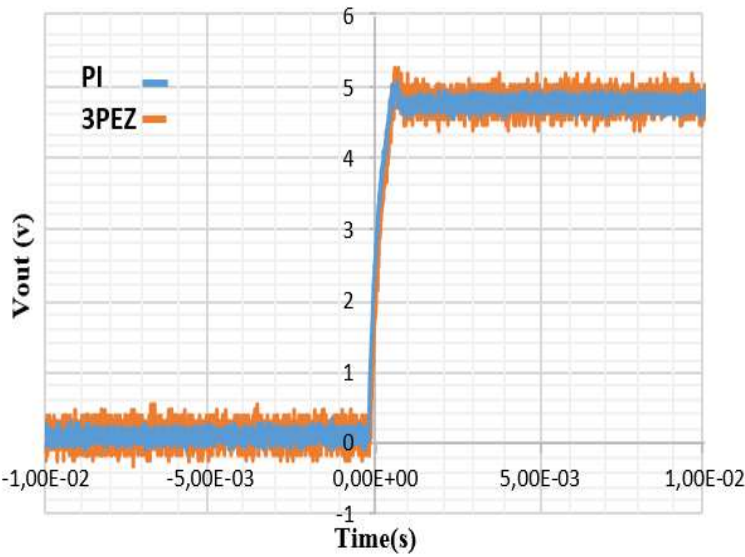

Fig. 12. Experimental results, voltage output with $3 \mathrm{P} 3 \mathrm{Z}$ and PI controllers

The Fig. 12 shows that with the $3 \mathrm{P} 3 \mathrm{Z}$ controller, the output voltage have more perturbation compare with PI controller, where $\mathrm{N}=8$ bit, we earned around $5 \%$.

The Fig. 13 shows the experimental results in case we modify the ADC resolution (bit number). We compare the buck voltage response with $\mathrm{PI}$ controller in case $\mathrm{N}=8$ bit and $\mathrm{N}=$ 12 bit.

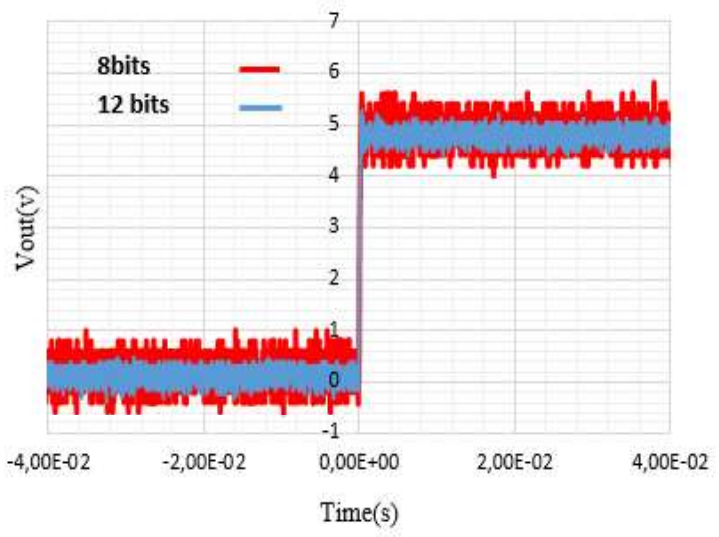

Fig. 13. Experimental result, voltage output with $\mathrm{PI}$ controller for $\mathrm{N}=8$ bit and $\mathrm{N}=12$ bit. 
We observe in Fig. 13, the noise level is depending on the $\mathrm{ADC}$ bit number, for $\mathrm{N}=12$ bit, the noise on output signal is very low comparing to $\mathrm{N}=8$ bit. we earn arraund $10 \%$.

In addition, for digital controlled power supply, quantization plays a significant role in its performance, stability and the noise level as shown by the experimental results.

\section{Comparaison $H$ infinty controller and PI controller}

The specter analyzer plots the different curve of the output voltage (Fig. 14). In the first step, we use a PI controller to regulate the system (blue curve) and in the second step, we use an $\mathrm{H}$-infinity controller. We superpose both of signals to assess the difference between the magnitudes. The simulation shows that the signal magnitude with PI controller is around $0.0057 \mathrm{~V}$. Or, with $\mathrm{H}$-infinity controller the magnitude is around $0,0043 \mathrm{~V}$. This experience proves that the $\mathrm{H}$-infinity controller reduces the noise level of the output system.

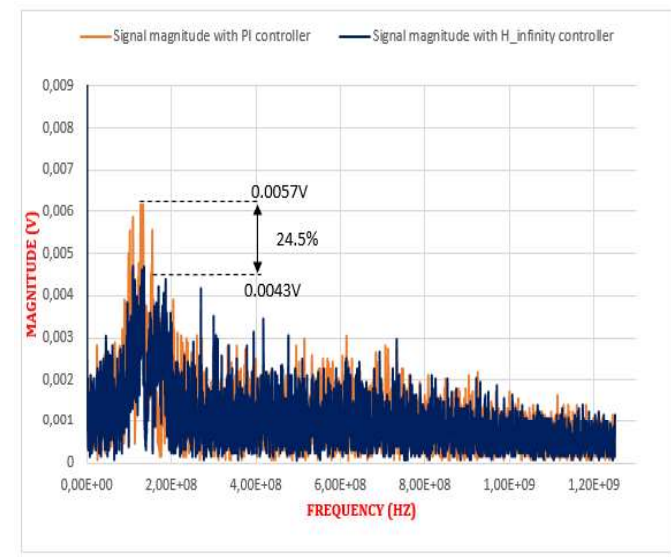

Fig. 14. Difference between system output spectrum for H-infinity controller (orange waveform) and PI controller (blue waveform)

In addition, the $\mathrm{H}$-infinity controller (robust control) is most perfect than PI controller (classical control).

\section{CONCLUSION}

This paper describes a methodology to determine the best technique control for a DC-DC buck converter. The first part of this study introduces the robust control design. The simulation part is very important to find the best controller model when the robust mode controller for the control of DCDC buck converter is designed and analyzed. The theoretical models are validated by means of simulations and experience. The robustness of the mode controlled buck converter system is tested for step load changes and input voltage variations. Fast dynamic response of the output voltage and robustness to noise disturbance and input voltage variations are obtained by using the robust $\mathrm{H}$-infinity controller.

In the future work, we add to this H-infinity controller a Kalman filter to estimate the voltage or the current in the loop controls, which allow removing hardware sensors.

\section{REFERENCES}

[1] Bendali Mahrez, Larouci Cherif Azib Toufik, Marchand Claude Coquery Gérard, "Design methodology of an interleaved buck converter for onboard automotive application, multi-objective optimization under multi-physic constraints", IET Electrical Systems in Transportation, Vol. 5 n², p. 53-60, June 2015.

[2] Larouci Cherif, Boukhnifer Moussa and Chaibet Ahmed, "Design of Power Converters by Optimization under Multi-physic Constraints; Application to a Two-Time Scales AC/DC-DC Converter", IEEE Transactions on Industrial Electronics, Vol.57 N¹1, p. 3746-3753, November 2010

[3] Wilmar Hernandez, "Robust Control Applied to Improve the Performance of a Buck-Boost Converter", Universidad Politécnica de Madrid EUIT de Telecomunicación Department of Circuits and Systems Ctra. Issue 6, Volume 7, June 2008.

[4] Chengwu Tao, Student Member, IEEE, and Ayman A. Fayed, Senior Member, IEEE, "PWM Control Architecture with Constant Cycle Frequency Hopping and Phase Chopping for Spur-Free Operation in Buck Regulators", IEEE, VOL. 21, N 9, September 2013.

[5] Adriano Pereira, Candido Duarte, Witold Gora "Performance Improvement of a Buck Converter using Kalman Filtering", Mestrado Integrado em Engenharia Eletrotécnica de Computadores, faculdade de engenharia da Universidade do Porto, October 2015.

[6] Ju-Hyun Park, Sung Jin Kim, Joo Young Lee, Sang Hyeon Park, Ju Ri Lee, Sang Yun Kim, Hong Jin Kim, and Kang-Yoon Lee "Output Noise Reduction Technique Based on Frequency Hopping in a DC-DC Converter for BLE Applications" IEIE Transactions on Smart Processing and Computing, vol. 4, no. 5, October 2015

[7] Salles Alain, "Conception d'éléments passifs magnétiques pour convertisseurs de faible puissance" Université Toulouse III - Paul Sabatier 26 Septembre 2008.

[8] Mark Lorenze Torregoza and Elmer R. Magsino "Effects of Quantization on Digital Buck Converter Switch Mode Power Supply", Electronics and Communications Engineering Department, College of Engineering, De La Salle University-Manila, Philippines, Journal of Automation and Control Engineering Vol. 2, No. 2, June 2014.

[9] Yongseok Choi, Naehyuck Chang, and Taewhan Kim, "DC-DC Converter-Aware Power Management for Low-Power Embedded Systems", IEEE Transactions On Computer-Aided Design Of Integrated Circuits And Systems, Vol. 26, No. 8, August 2007.

[10] Liping Guo "Design and Implementation of Digital Controllers for Buck and Boost Converters Using Linear and Nonlinear" the Graduate Faculty of Auburn University Control Methods Auburn, Alabama, August 2006.

[11] Nuttapon Phurahong, Somyot Kaitwanidvilai and Atthapol Ngaopitakkul "Fixed Structure Robust 2DOF H-infinity Loop Shaping Control for ACMC Buck Converterusing Genetic Algorithm" the International MultiConfernce of Engineers and Computer Scientists 2012 Vol II, IMECS 2012 Hong Kong.

[12] Infineon technology user manuel "Synchronous buck converter with XMC Digital Power Explorer Kit”, costumer documentation V1.0,2015.

[13] Olranthichachat, Piyapong, and Somyot Kaitwanidvilai. "Structure specified robust $\mathrm{H}$ infinity loop shaping control of a MIMO electrohydraulic servo system using particle swarm optimization." Proceedings of the International Multi Conference of Engineers and Computer Scientists. Vol. 2. 2011.

[14] A. Megretski 6.245: "multivariable control systems, Tustin transform" massachusetts institute of technology department of electrical engineering and computer science. Version of April 3, 2004. 